\title{
The Implementation of Satellite Data (Land SAF) in the INCA Surface Temperature for Austria
}

\author{
Jing Liu ${ }^{1}$, Jingyu Bai ${ }^{1}$, Yong Wang ${ }^{2}$, and Alexander Kann ${ }^{2}$ \\ ${ }^{1}$ Public Weather Service Center, Chinese Meteorology Administration, Beijing, China \\ shunying0309@163.com, baijy@weather.com.cn \\ ${ }^{2}$ Central Institute for Meteorology and Geodynamics, Vienna, Austria \\ yong.wang62@gmail.com, alexander.kann@zamg.ac.at
}

\begin{abstract}
The Ground Temperature module (TG) of the current INCA only used the observations from stations in Austria. In this paper, the combinations of stations and satellite observations from $4^{\text {th }}$ to $26^{\text {th }}$ December 2011 are used in the TG module, and its results are analyzed. The retrievals from satellite can be used as the complement of observations under specific surface conditions, and which kinds of conditions are feasible to retrieve LST products from satellite have to be explored. There are lower errors for satellite in the areas of less than $500 \mathrm{~m}$, and higher errors in the areas from $500 \mathrm{~m}$ to $1000 \mathrm{~m}$. The satellite retrievals are lower than the values from stations, maybe it exist systematic errors in the algorithm of satellite. INCA is a relatively young system still under development. The further improvements and refinements will be added in a step by-step process in the future.
\end{abstract}

Keywords: INCA, satellite data, surface temperature.

\section{Introduction of INCA}

The Integrated Nowcasting System for the Central European Area (INCA-CE) project aims at reducing adverse effects of weather-related natural disasters (e.g. windstorms, flooding, icing, drought) by establishing a state-of-the-art, high resolution, real-time analysis and forecast system on atmospheric, hydrological, and surface conditions. The project will implement a transnational information system as well as applications for different social and economic sectors to reduce risks of major economic damage.

The INCA is being developed primarily as a means of providing improved numerical forecast products in the nowcasting range (up to $+4 \mathrm{~h}$ ) and very short range (up to about $+12 \mathrm{~h}$ ) even though it adds value to NWP forecasts up to $+48 \mathrm{~h}$ through the effects of downscaling and bias correction [1-4]. The INCA system adds value to the classical NWP forecast by providing (a) high-resolution analyses $(1 \mathrm{~km})$, (b) nowcasts, and (c) improved forecasts both within and beyond the nowcasting range. The first version of the INCA system became operational in 2005. In the years 2006-2008, several major extensions and modifications were made to the system [5-7], such as the additional field precipitation type [5], the use of a surface layer index in the temperature and humidity analysis, or the elevation dependence of precipitation. Based on station 
observations and remote sensing data it now provides three-dimensional hourly analyses and nowcasts of temperature, humidity, and wind, two-dimensional hourly analyses and nowcasts of global radiation, and two-dimensional 15-min analyses and nowcasts of precipitation, precipitation type, and cloudiness.

INCA is a relatively young system still under development. The further improvements and refinements will be added in a step by-step process in the future [8]. The Ground Temperature module (TG) of the current INCA only used the observations from stations in Austria. In order to improve the 3D temperature analysis in complex terrain, especially during inversion situations, using the observations from satellite is the best available way to solve this difficult problem. In this paper, the combinations of stations and satellite observations are used in the TG module, and its results are analyzed.

\section{Materials and Methods}

\subsection{NWP Model Output}

For the three-dimensional INCA analyses of temperature, humidity, and wind, NWP forecast fields provide the first guess on which corrections based on observations are superimposed. The NWP fields are 1-hourly, at a resolution of $9.6 \mathrm{~km}$, with 45 levels in the vertical (Wang et al. 2006). Four ALADIN forecast runs per day are performed (00Z, 06Z, 12Z, 18Z). The $00 \mathrm{Z}$ and $12 \mathrm{Z}$ runs are integrated to $+72 \mathrm{~h}$, the $06 \mathrm{Z}$ and $18 \mathrm{Z}$ runs to $+60 \mathrm{~h}$. Post-processed fields are available roughly $4 \mathrm{~h}$ after analysis time. ALADIN forecast fields used in INCA are geopotential, temperature, relative humidity, $\mathrm{u}-, \mathrm{v}-, \mathrm{w}-\mathrm{wind}$ components (3-d fields), $2 \mathrm{~m}$ temperature and relative humidity, u-, v$10 \mathrm{~m}$-wind components, precipitation, total cloudiness, low cloudiness, and surface temperature (2-d fields). The three-dimensional fields are provided on pressure surfaces with a vertical resolution of $50 \mathrm{hPa}$ up to $600 \mathrm{hPa}$, and aresolution of $100 \mathrm{hPa}$ above.

\subsection{Surface Station Observations}

The single most important data source for the INCA system are surface stations. About 275 automated stations observations are used. In the vertical, the network of stations spans most of the topographic range in Austria, with highest stations Brunnenkogel $(3440 \mathrm{~m})$, and Sonnblick $(3105 \mathrm{~m})$. Although the distribution of stations is biased towards valley locations there is a sufficient number of mountain stations to construct three-dimensional correction fields to the NWP model output, based on observations. The station density versus elevation roughly corresponds to the area height distribution of the topography up to about $1500 \mathrm{~m}$. At higher elevations, the station density is lower than it ideally should be according to the area-height distribution.

\subsection{Satellite Data}

The ECUMETSAT Polar System (EPS) is Europe's first polar orbiting operational meteorological satellite, the first of which was successfully launched on October 19, 
2006. The retrieval of LST is in the thermal infrared window (MetOp/AVHRR-3 channels $4(10.3-11.3 \mu \mathrm{m})$ and $5(10.5-11.5 \mu \mathrm{m}))$. The version2.0 for AVHRR LST products is valid on 10/Jan/2008, and its characteristics are described in Table 1. Further details may be found in the website (http://landsaf.meteo.pt). Theoretically, LST values can be determined twice per day from MetOp. However, fewer observations are generally available due to cloud cover contamination.

Table 1. Summary of Product Characteristics - AVHRR LST

\begin{tabular}{llllll}
\hline coverage & $\begin{array}{l}\text { Resolution } \\
\text { Temporal }\end{array}$ & Spatial & Range & Factors & Appended data \\
\hline $\begin{array}{l}\text { Europe \& } \\
\text { High latitudes }\end{array}$ & $1 / 2$ day & $\begin{array}{l}1 * 1 \mathrm{~km} \text { at } \\
\text { nadir }\end{array}$ & $-80-70^{\circ} \mathrm{C}$ & 100 & $\begin{array}{l}\text { Quality control } \\
\text { information }\end{array}$ \\
\hline
\end{tabular}

The LST data in this study are from $4^{\text {th }}$ to $26^{\text {th }}$ December 2011 . In order to matching the observations from stations, the time window of satellite data is \pm 30 minutes at exact hour. Running the ground temperature module (TG) needs the 2 meters temperature $(\mathrm{T} 2 \mathrm{~m})$, which is not retrieved from AVHRR. The available solution is obtaining $\mathrm{T} 2 \mathrm{~m}$ fields from INCA analysis fields interpolated by the output of ALADIN model to match the satellite LST values, and then run the INCA TG module to get the TG analysis field.

\section{$3 \quad$ Results}

The different input data from $4^{\text {th }}$ to $26^{\text {th }}$ December 2011 are used to run INCA TG module, obtaining the analysis fields of ground temperature, which are based on only model data, model and stations data, model and satellite, total data, respectively.

The better cases are shown in Fig 1and Fig 2, and the worse cases are shown in Fig 3. Most of the ground temperature values based on the satellite data are lower than those values on the stations data. The order of magnitude for good cases is much smaller than that for bad cases. Comparing the values of satellite with stations, most of values for good cases are within $5^{\circ} \mathrm{C}$ (Fig 1 and Fig 2), and many values for bad cases are beyond $10^{\circ} \mathrm{C}$. At 20:00 on $13^{\text {th }}$ December, the mean deviation is $-1.76^{\circ} \mathrm{C}$, and the mean absolute difference is $2.54^{\circ} \mathrm{C}$. About $89 \%$ of the values are less than $5^{\circ} \mathrm{C}$, and about $65 \%$ are less than $2^{\circ} \mathrm{C}$. The best case is at 19:00 on $23^{\text {th }}$ December, the mean deviation is $-1.23^{\circ} \mathrm{C}$, and the mean absolute difference is $1.96^{\circ} \mathrm{C}$; Only two values exceed $-5^{\circ} \mathrm{C}$, and the others are within $5^{\circ} \mathrm{C}$ (about $94 \%$ of the total). The worst case is at 20:00 on $21^{\text {th }}$ December, the mean deviation is $-13.70^{\circ} \mathrm{C}$; all values of satellite are lower than those of stations; more than half of the differences are larger than $10^{\circ} \mathrm{C}$. 

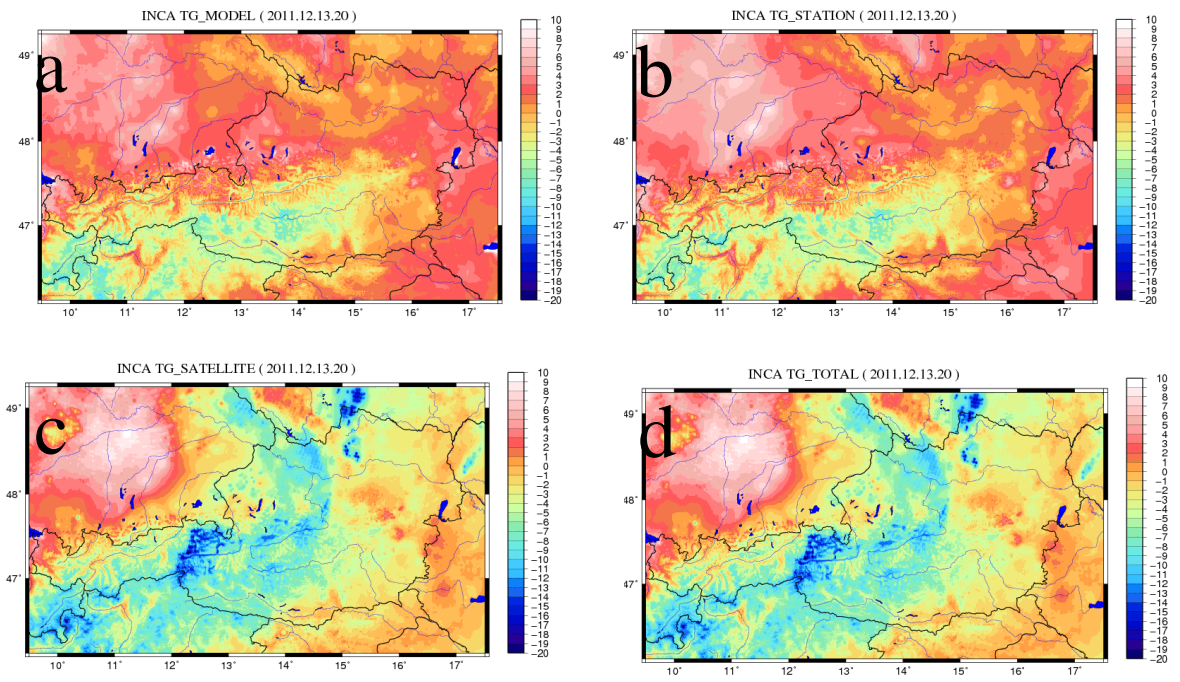

Fig. 1. Different Analysis fields of INCA ground temperature, a: only model data, b: model and stations data, c: model and satellite data, c: model, stations and satellite data
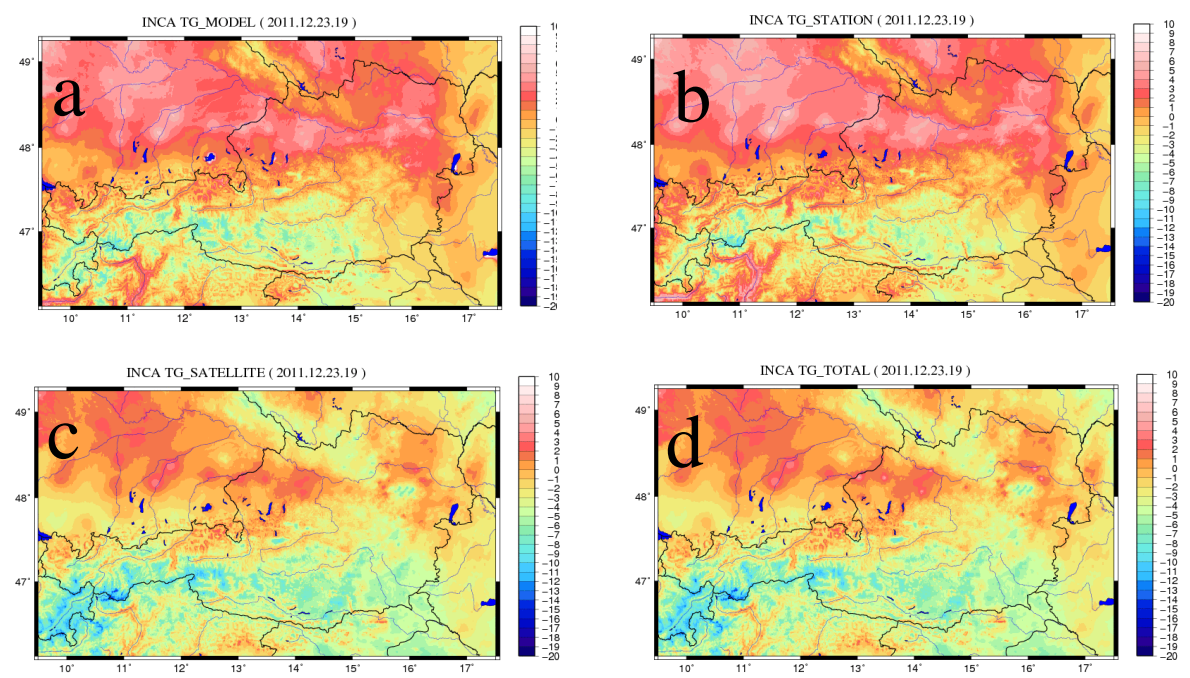

Fig. 2. The same as above 

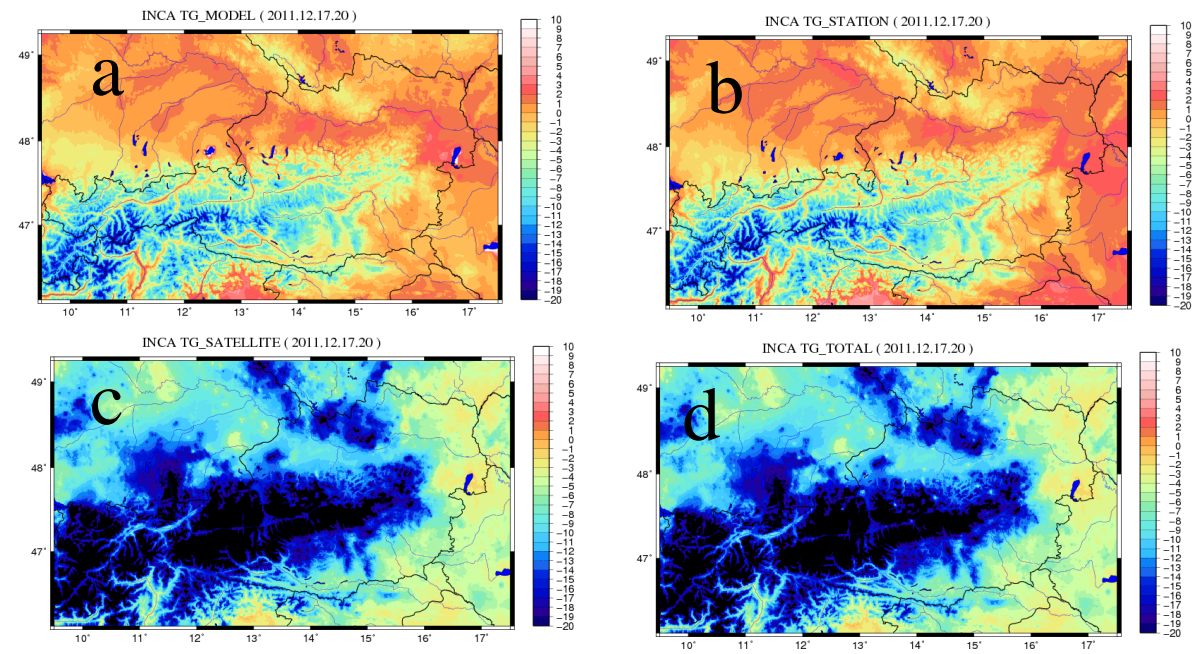

Fig. 3. The same as above (a bad case)

\section{Discuss}

Based on the analysis of above cases, LST qualities are sometimes good and sometimes bad. The satellite retrieval results may be affected by many factors, such as altitude, aerosols, weather conditions, surface types and so on. Here, the relations between TG differences and altitude height are discussed(Fig 4 and Fig 5).

The lower deviations of TG appear in the areas of less than $500 \mathrm{~m}$. With the altitude increasing from $500 \mathrm{~m}$ to $1000 \mathrm{~m}$, the differences of TG have a strong fluctuation, emerging the extreme values for most of the cases. That is to say, the quality of LST retrieval is not good in the case of higher altitude. The reason maybe is the surface types or vegetations are difficult to predicate. For low-altitude areas, it is possible to use the LST data as the complement of observations; for high altitude, it needs to do many works when using the LST data.
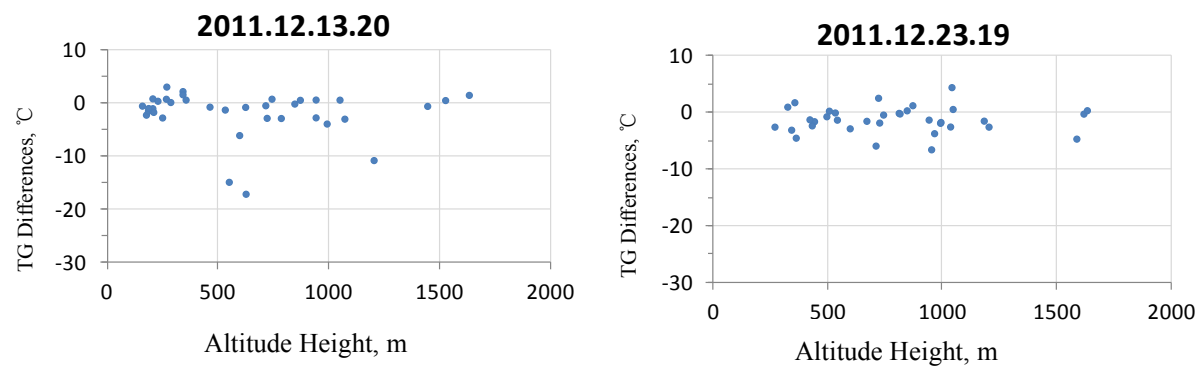

Fig. 4. Two good cases for the differences of ground temperature (satellite minus stations) varying with the height of altitude 

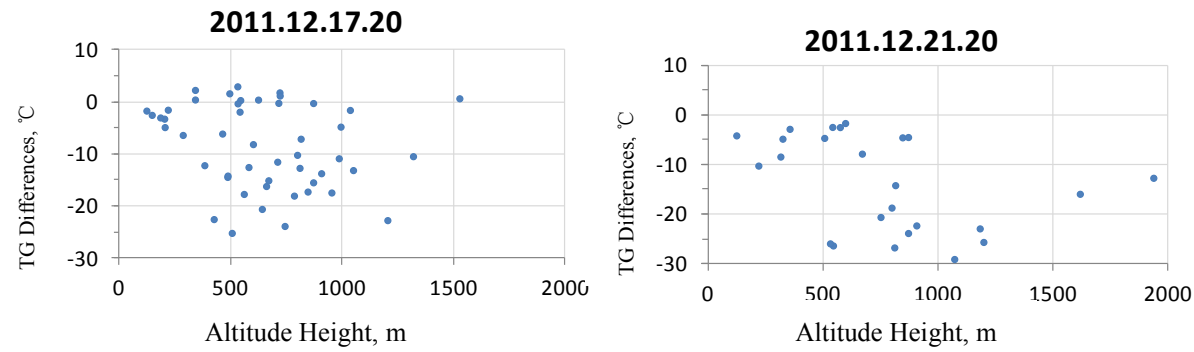

Fig. 5. The same as above, except for bad cases

When running TG module based on satellite data, it needs the input parameters of the 2 meters temperature (T2m) to derive the differences field of ground and $\mathrm{T} 2 \mathrm{~m}$ temperature. Due to no T2M product retrieved from satellite, we obtain T2M data from INCA analysis field. Maybe it is another factor to affect the TG analysis field derived by model and satellite data.

\section{Conclusions}

1) The LST differences of satellite and stations for good cases are lower than those for bad cases. For two good cases of this study, the mean error is about $-1.5^{\circ} \mathrm{C}$; about $89 \%$ of the values are less than $5^{\circ} \mathrm{C}$, and about $65 \%$ are less than $2^{\circ} \mathrm{C}$. That is to say, the retrievals from satellite can be used as the complement of observations under specific conditions. We have to explore which kinds of conditions are feasible to retrieve LST products from satellite.

2) The qualities of satellite values are related with altitude. There are lower errors for satellite in the areas of less than $500 \mathrm{~m}$, and higher errors in the areas from $500 \mathrm{~m}$ to $1000 \mathrm{~m}$. For low-altitude areas, it is possible to use the LST data as the complement of observations; for high altitude, it needs to do many works when using the LST data.

3) Whether good or bad cases, the satellite retrievals are lower than the values from stations. Maybe it exist systematic errors in the algorithm of satellite. We can analyze the factors affecting the algorithm of satellite, and find out the systematic errors.

4) More than one year of satellite LST should be analyzed and verified. Many factors such as surface types, weather conditions, aerosols, and so on, can affect the LST results retrieved from satellite. According to a long series data, the systematic errors in the data can be obtained for different regions with seasons.

Acknowledgment. The Land SAF data were obtained from http://landsaf.meteo.pt. This work was supported by the integrated Nowcasting System for the Central European Area (INCA-CE) project and the infrastructure project of China Meteorological Administration (141161000016). I'd like to thank Benedikt Bica and Xin Yan for help me dealing with the problems of the INCA-TG module, and thank Alex and andrew for helping me prepare satellite data. 


\section{References}

1. Golding, B.W., Nimrod: A system for generating automated very short range forecasts. Meteorol. Appl. 5, 1-16 (1998)

2. Haiden, T., Pistotnik, G.: Parameterization of elevation effects in short-duration precipitation analysis. In: Preprints, 13th Conference on Mountain Meteorology. Amer. Meteor. Soc., Whistler 4p. (2008)

3. Haiden, T., Kann, A., Pistotnik, G., et al.: Integrated nowcasting through comprehensive Analysis (INCA) System description (2009)

4. Sharples, J.J., Hutchinson, M.F., Jellett, D.R.: On the horizontal scale of elevation dependence of Australian monthly precipitation. J. Appl. Meteor. 44, 1850-1865 (2005)

5. Skoda, G., Filipovic, N.: Multi-data precipitation analysis. Austrian Academy of Sciences, Final report, Vienna, 17 p. (2007)

6. Steinacker, R., Ratheiser, M., Bica, B., Chimani, B., Dorninger, M., Gepp, W., Lotteraner, C., Schneider, S., Tschannett, S.: Downscaling meteorological information over complex terrain with the fingerprint technique by using a priori knowledge. Mon. Wea. Rev. 134, 2758-2771 (2006)

7. Wang, Y., Haiden, T., Kann, A.: The operational limited area modelling system at ZAMG: ALADIN-AUSTRIA, Österr. Beiträge zu Meteorologie und Geophysik, Heft 37, 33p. (2006)

8. Whiteman, C.D., Haiden, T., Pospichal, B., Eisenbach, S., Steinacker, R.: Minimum temperatures, diurnal temperature ranges and temperature inversions in limestone sinkholes of different sizes and shapes. J. Appl. Meteor. 43, 1224-1236 (2004) 